\title{
Defects in Motoneuron-Astrocyte Interactions in Spinal Muscular Atrophy
}

\author{
Chunyi Zhou, ${ }^{\star}$ Zhihua Feng, ${ }^{\star}$ and $\mathbb{C}$ Chien-Ping Ko \\ Section of Neurobiology, Department of Biological Sciences, University of Southern California, Los Angeles, California 90089-2520
}

Spinal muscular atrophy (SMA) is a motoneuron disease caused by loss or mutation in Survival of Motor Neuron 1 (SMN1) gene. Recent studies have shown that selective restoration of SMN protein in astrocytes partially alleviates pathology in an SMA mouse model, suggesting important roles for astrocytes in SMA. Addressing these underlying mechanisms may provide new therapeutic avenues to fight SMA. Using primary cultures of pure motoneurons or astrocytes from SMN $\Delta 7$ (SMA) and wild-type (WT) mice, as well as their mixed and matched cocultures, we characterized the contributions of motoneurons, astrocytes, and their interactions to synapse loss in SMA. In pure motoneuron cultures, SMA motoneurons exhibited normal survival but intrinsic defects in synapse formation and synaptic transmission. In pure astrocyte cultures, SMA astrocytes exhibited defects in calcium homeostasis. In motoneuron-astrocyte contact cocultures, synapse formation and synaptic transmission were significantly reduced when either motoneurons, astrocytes or both were from SMA mice compared with those in WT motoneurons cocultured with WT astrocytes. The reduced synaptic activity is unlikely due to changes in motoneuron excitability. This disruption in synapse formation and synaptic transmission by SMN deficiency was not detected in motoneuron-astrocyte noncontact cocultures. Additionally, we observed a downregulation of Ephrin B2 in SMA astrocytes. These findings suggest that there are both cell autonomous and non-cell-autonomous defects in SMA motoneurons and astrocytes. Defects in contact interactions between SMA motoneurons and astrocytes impair synaptogenesis seen in SMA pathology, possibly due to the disruption of the Ephrin B2 pathway.

Key words: astrocytes; ephrin B2; motoneurons; spinal muscular atrophy; synapses; synaptic transmission

\section{Significance Statement}

Astrocytes have been implicated in various neurological diseases, including spinal muscular atrophy (SMA), a childhood motoneuron disease. However, how bidirectional motoneuron-astrocyte communications may contribute to SMA disease mechanisms is unclear. Using in vitro culture systems, we demonstrate that SMN deficiency affects both astrocytes and motoneurons, as well as their contact interactions, leading to defects in synapse formation and synaptic transmission onto motoneurons, probably through downregulation of Ephrin B2 expression in astrocytes. Our work suggests that defects in motoneuron-astrocyte interactions exacerbate SMA synaptic pathology and that therapeutic restoration of SMN should target multiple cell types, including astrocytes.

\section{Introduction}

Spinal muscular atrophy (SMA) is an autosomal recessive motoneuron disease characterized by loss of synapses and motoneurons in the spinal cord, in addition to neuromuscular junction

Received Sept. 21, 2015; revised Jan. 14, 2016; accepted Jan. 22, 2016.

Author contributions: C.Z., Z.F., and C.-P.K. designed research; C.Z. and Z.F. performed research; C.Z., Z.F., and C.-P.K. analyzed data; C.Z., Z.F., and C.-P.K. wrote the paper.

This work was supported by Cure SMA, the Dhont Family Foundation, and the Spinal Muscular Atrophy Foundation. We thank Dr. David McKemy and Yuening Yang for assistance with calcium imaging experiments; Dr. Donald B. Arnold and Shanxi Feng for assistance with anti-PSD95 staining; and Chiara Mazzasette, Pei-Fen Yen, and Steven Lam for valuable comments and discussion.

The authors declare no competing financial interests.

${ }^{*}$ C.Z. and Z.F. contributed equally to this work.

Correspondence should be addressed to Dr. Chien-Ping Ko, Department of Biological Sciences, University of Southern California, 3641 Watt Way, HNB 209, Los Angeles, CA 90089-2520. E-mail: cko@usc.edu.

DOI:10.1523/JNEUROSCI.3534-15.2016

Copyright $\odot 2016$ the authors $\quad 0270-6474 / 16 / 362543-11 \$ 15.00 / 0$ defects and skeletal muscle atrophy (Crawford and Pardo, 1996; Tisdale and Pellizzoni, 2015). It has been well established that SMA is caused by the loss or mutation of the telomeric Survival of Motor Neuron (SMN1) gene with the retention of the centromeric SMN2 gene, which results in a low level of full-length SMN protein (Lefebvre et al., 1995; Crawford and Pardo, 1996). Currently, there are no effective therapies available for this leading genetic cause of infant mortality.

Although SMN deficiency mainly affects motoneurons, motoneuron-specific SMN restoration only modestly extends the survival of SMA mice (Gogliotti et al., 2012; Martinez et al., 2012; Paez-Colasante et al., 2013). Conversely, neuronal depletion of SMN protein results in synaptic transmission defects but does not significantly affect animal survival (Park et al., 2010). These findings suggest that reduced SMN may impair not only motoneurons but also other components in the motor circuitry. Indeed, 
recent studies have implicated that non-neuronal cells in the neuromuscular circuit, such as glial cells (McGivern et al., 2013; Hunter et al., 2014; Rindt et al., 2015), muscles (Nicole et al., 2003; Ruiz et al., 2010; Boyer et al., 2014), and sensory afferent connections (Ling et al., 2010; Mentis et al., 2011; Gogliotti et al., 2012) contribute to SMA pathogenesis. Furthermore, emerging evidence suggests that SMA is a multisystem disorder, including defects in non-neuronal organs, such as the heart, lung, liver, pancreas, intestines, vasculature, and bone (Hamilton and Gillingwater, 2013; Shababi et al., 2014; Iascone et al., 2015).

Astrocytes play critical roles in neuron survival, synapse formation, and maturation through diffusible factors and contactmediated mechanisms (Barres, 2008; Allen and Barres, 2009; Clarke and Barres, 2013). Thus, dysfunction of astrocytes likely leads to synapse and/or neuronal loss. This has been implicated in various neurological diseases, such as ALS, Rett syndrome, fragile X syndrome, and Down's syndrome (Ballas et al., 2009; Ilieva et al., 2009; Garcia et al., 2010; Jacobs and Doering, 2010). A recent study showed that selective increase of SMN in astrocytes significantly extends the life span of severe SMA mice (SMN $\Delta 7$ mice) and partially rescues synapse loss onto spinal motoneurons and neuromuscular junction defects (Rindt et al., 2015). However, the mechanisms underlying astrocyte-mediated rescue in SMA remain unknown. Given that the loss of synapses on motoneurons is one of the key pathological features seen in SMA mice (Ling et al., 2010; Mentis et al., 2011), the role and interactions of astrocytes with motoneurons in this context need to be addressed.

To study intrinsic defects of motoneurons and astrocytes in SMA, we used primary cultures of pure motoneurons or astrocytes from SMN $\Delta 7$ mice, a severe SMA mouse model (Le et al., 2005). To study the interactions between motoneurons and astrocytes, we used mixed cocultures with wild-type (WT) or mutant motoneurons and astrocytes. Neuron and astrocyte cocultures provide a simplified model to understand the complex cross talk between them (Ullian et al., 2001; Di Giorgio et al., 2007; Nagai et al., 2007; Ballas et al., 2009; Haidet-Phillips et al., 2011). Cocultures between motoneurons and astrocytes can allow us to study and differentiate whether cross talk is mainly mediated via direct interaction (contact cocultures) or by diffusible factors from astrocytes. Here, we have found that SMN deficiency results in cell-autonomous defects of both motoneurons and astrocytes, as well as non-cellautonomous defects observed in contact interactions between motoneurons and astrocytes. These interactions are likely mediated by a downregulation of Ephrin B2. The results suggest that, beyond defects in spinal motoneurons, SMA synaptic pathology is also characterized by astrocytes that are defective in promoting synaptogenesis on motoneurons. Thus, astrocytes, like motoneurons, could be a therapeutic target for SMA.

\section{Materials and Methods}

Animals. The Institutional Animal Care and Use Committee of the University of Southern California approved the care and use of animals and the experimental protocol of this study. $S M N \Delta 7$ mice were purchased from The Jackson Laboratory (\#005025, FVB.Cg-Tg(SMN2* $\delta 7)$

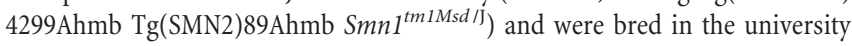
animal facility. Mouse genotypes were determined as described previously (Le et al., 2005). Food and water were provided ad libitum; daylight cycle was set to 6:00 A.M.to 6:00 P.M

Primary astrocyte culture. Isolated spinal cord astrocytes were prepared as described previously with some modifications (Ullian et al., 2004). WT and SMA mice of either sex were killed at postnatal day 5 with Euthasol (Virbac). Whole spinal cords were removed and immersed in ice-cold HBSS (Invitrogen ) with $1 \%$ glucose. After meninges were removed, spinal cords were minced and trypsinized $(0.25 \%)$ for $30 \mathrm{~min}$ at $37^{\circ} \mathrm{C}$, triturated with glass pipettes, and centrifuged $1000 \mathrm{rpm}$ at room temper- ature for $15 \mathrm{~min}$ (Hettich, Rotofix 32A). The pellets were resuspended and transferred to DMEM (Invitrogen ) supplemented with 10\% FBS (Invitrogen ) in tissue culture flasks (BD Biosciences). When the cells reached confluence, the flasks were shaken at $250 \mathrm{rpm}$ for $6-8 \mathrm{~h}$ to remove contaminating cells. The astrocytes were harvested and reseeded onto 24 well culture plates, $35 \mathrm{~mm}$ dishes, or $12 \mathrm{~mm}$ glass coverslips precoated with $0.01 \%$ poly-L-lysine. The astrocytes were fed twice a week.

Primary motoneuron culture. Spinal cord motoneurons were prepared as described previously (Ullian et al., 2004). Briefly, spinal cords were dissected from embryonic day 13-14 WT or SMA mice and incubated into ice-cold EBSS (Invitrogen). Spinal cords from 4 or 5 embryos with the same genotype were pooled together, minced, and digested in 20 $\mathrm{U} / \mathrm{ml}$ papain (Sigma) $/ \mathrm{EBSS}$ at $37^{\circ} \mathrm{C}$ for $30 \mathrm{~min}$, then were triturated and centrifuged (1000 rpm for $10 \mathrm{~min}$ ). After the pellets were suspended with EBSS, the cell suspensions were layered $>8.5 \%$ metrizamide and centrifuged $1100 \mathrm{rpm}$ for $15 \mathrm{~min}$. The supernatant and the cell interface layers were diluted into the equal volume of EBSS. Cells were centrifuged for another $10 \mathrm{~min}$ at $1000 \mathrm{rpm}$ at room temperature. The resulting motoneuron pellets were resuspended and cultured on poly-L-lysine, and laminin-precoated $12 \mathrm{~mm}$ coverslips with a density of 6000-8000 cells per coverslip. Motoneurons were maintained in neurobasal medium supplemented with B27 (Invitrogen ), BDNF (10 ng/ml), GDNF (10 $\mathrm{ng} / \mathrm{ml}$ ), and CNTF (10 ng/ml) (Invitrogen). Only half of media was replaced with fresh media every other day. Motoneuron astrocyte contact or noncontact cocultures were performed as previously described (Ullian et al., 2004; Környei et al., 2005). For motoneuron astrocyte direct contact cocultures, motoneurons were seeded directly onto astrocyte monolayers on $12 \mathrm{~mm}$ glass coverslips. For motoneuron astrocyte noncontact cocultures, motoneuron inserts were placed into confluent astrocytes for cocultures. Motoneuron growth media were the same for both contact and noncontact cocultures.

Electrophysiological recording. Neurons were visualized with phasecontrast illumination under an Olympus microscope equipped with $10 \times$ and $40 \times$ air objectives. The electrophysiological signals of neurons were recorded with whole-cell patch-clamp techniques. The setup has an Axopatch 200B amplifier (Molecular Devices), a Digidata 1200 analog-todigital converter (Molecular Devices), and is controlled by Clampex 8.0 (Molecular Devices). The patch electrode had a resistance of 5-7 $\mathrm{m} \Omega$, when filled with the intrapipette solution as follows (in $\mathrm{mM}$ ): 135 potassium gluconate, 5 EGTA, $0.5 \mathrm{CaCl}_{2}, 10 \mathrm{HEPES}, 2 \mathrm{Mg}$-ATP, and $0.1 \mathrm{GTP}$. The extracellular solution contained the following (in mM): $140 \mathrm{NaCl}, 5$ $\mathrm{KCl}, 10$ HEPES, $2 \mathrm{MgCl}_{2}, 2 \mathrm{CaCl}_{2}, 10$ glucose, $\mathrm{pH}$ 7.3. Drugs were added in external solution and applied with bath perfusion. Action potentials were recorded in current-clamp mode. Miniature EPSCs (mEPSCs) were recorded from voltage-clamped neurons (at $-50 \mathrm{mV}$ ) in the presence of TTX $(1 \mu \mathrm{M})$. Evoked action potential was recorded with injection of 800 ms current pulse in current-clamp mode. Change of membrane potential was evoked by current steps from $-20 \mathrm{pA}$ to $100 \mathrm{pA}$ with a $10 \mathrm{pA}$ increment. All recordings were performed at room temperature.

The mEPSCs and action potential were screened, counted, and analyzed using the Event Detection feature in Clampfit 10.3 after the traces were low-pass filtered at $2 \mathrm{kHz}$. The frequency and amplitude of mEPSCs and action potentials recorded from motoneurons were compared among different culture conditions with one-way ANOVA. Rheobase current for generation of action potential was defined as minimal current required to produce an action potential. Voltage threshold of action potential was measured at the beginning of upward rise of action potential. The input membrane resistance of the neuron was calculated by change of membrane potential in response to injected current, according to Ohm's law.

Fluorescent immunocytochemistry. Cultures were fixed with 4\% PFA for $10 \mathrm{~min}$, permeabilized with $0.01 \%$ Triton X-100 in PBS for $5 \mathrm{~min}$, and blocked with $10 \%$ serum in PBS for $30 \mathrm{~min}$. The cultures were incubated $1 \mathrm{~h}$ at room temperature with following primary antibodies: rabbit anti-Hb9 antibody (1:200, Millipore), rabbit anti-synaptophysin (1:200, Synaptic Systems), mouse anti-PSD95 (1:1000, NeuroMab), and rabbit anti-S100 antibody (1:200, Sigma). The samples then were incubated with fluorescence-conjugated secondary antibodies at room temperature 
Table 1. Primers for the target genes amplification

\begin{tabular}{|c|c|c|c|c|}
\hline Genes & Forward primer & Reverse primer & $\mathrm{Tm}$ & $\begin{array}{l}\text { Product } \\
\text { (bp) }\end{array}$ \\
\hline $\begin{array}{l}\text { Ephrin-A3 } \\
\text { (Carmona et al., } \\
\text { 2009) }\end{array}$ & GCAGCACGCCTCGCACAGC & AAGGATGTAGGCCCCACAGCA & 65 & 171 \\
\hline $\begin{array}{l}\text { Ephrin-A4 } \\
\qquad \text { (Du et al., 2012) }\end{array}$ & CAGCGCTACACACCCTTCCC & GTGATGACCCGCTCTCCTTG & 65 & 142 \\
\hline $\begin{array}{l}\text { Ephrin-B2 } \\
\text { (Pickles, 2003) }\end{array}$ & TTGAAAAGCCAAAGGTCAAAC & CTCTAAGAGGTGGGCCATGTG & 55 & 227 \\
\hline
\end{tabular}

for $1 \mathrm{~h}$. The samples were immersed in Vectorshield mounting medium (Vector Laboratories) and were covered by coverslips.

Samples processed with fluorescent immunocytochemistry were imaged with a confocal microscope (Zeiss). ImageJ (National Institutes of Health) was used for image processing. Synaptic puncta were counted manually as described previously (Ullian et al., 2004). Neuron survival at 12 DIV was normalized as a percentage of initial number counted at day 0 . All data were obtained from three coverslips at each experiment and at least three different cell preparations.

$R T-P C R$ of individual genes. Total RNA was extracted from cultured astrocytes using TRIzol reagent (Invitrogen) and treated with DNase using the DNA-free kit (Thermo Fisher Scientific); $2 \mu \mathrm{g}$ of total RNA was reverse-transcribed using the SuperScript III (Invitrogen) to synthesize cDNA. Quantitative PCR was performed using a CFX96 real-time PCR detection system (Bio-Rad). The relative expression level for each gene was calculated using the $2^{-\Delta \Delta C t}$ method (Livak and Schmittgen, 2001), and all PCR values were normalized with the housekeeping genes, such as GAPDH or actin (Table 1) (Pickles, 2003; Carmona et al., 2009; Du et al., 2012).

Calcium imaging. Astrocytes or motoneurons (WT and SMA) on 12 $\mathrm{mm}$ glass coverslips were washed with extracellular solution the same as one used for electrophysiological recordings, and then loaded for $30 \mathrm{~min}$ at room temperature with $5 \mu \mathrm{M}$ fura-2 (Invitrogen) and $1 \mathrm{mg} / \mathrm{ml} \mathrm{BSA}$ in extracellular solution. Pseudo-color fluorescence ratio at excitation of 340 and $380 \mathrm{~nm}$ was obtained with Olympus IX70 fluorescent microscope and Metafluor software (Molecular Devices). All data presented were obtained from three coverslips of each experiment and at least three different cell preparations.

Statistical analysis. Unpaired $t$ test or one-way ANOVA as needed was applied with Prism 5.0 software. The $p$ values $<0.05$ are considered significant. Results are expressed as mean \pm SEM.

\section{Results}

\section{SMN deficiency in motoneurons impairs synapse formation} and function

To determine whether the synapse loss onto spinal motoneurons seen in SMN $\Delta 7$ mice (Ling et al., 2010; Mentis et al., 2011) is a cellautonomous defect of SMA motoneurons, motoneurons were isolated from spinal cords of WT and SMA mice at embryonic day (E) 13-14 and cultured for 12 DIV. First, we quantified the number of synapses formed onto motoneurons. Synapses were immunostained with antibodies against presynaptic and postsynaptic markers, synaptophysin (Fig. 1A, green fluorescence) and PSD95 (Fig. 1A, red fluorescence), respectively. Synapse numbers were counted within the area twice the diameter of the cell body. The vast majority of presynaptic synaptophysin puncta overlapped with postsynaptic PSD95 staining on the soma and along the neurite of motoneurons (Fig. $1 A$ ), suggesting that synaptophysin puncta correspond to structural synapses. As shown in Figure $1 B$, a significant reduction $(\sim 20 \%)$ in synapse number was observed on SMA motoneurons compared with WT motoneurons $(p<0.001)$. Next, the viability of WT and SMA motoneurons was measured to rule out the possibility of motoneuron loss, which in turn could cause a reduction of synapse number on SMA motoneurons. There was no difference in the survival of WT and SMA motoneurons at $12 \mathrm{DIV}(p=0.75)$ (Fig. 1C). Additionally, the difference in synapse numbers was not due to the variation in the purity of motoneurons because $>90 \%$ of Nissl-positive neurons were also stained by $\mathrm{Hb} 9$, a motoneuron marker (data not shown).

To investigate whether the reduction of synapses, formed onto SMA motoneurons, leads to the decrease in synaptic activity, we recorded synaptic currents from WT and SMA motoneurons at 12-14 DIV using the whole-cell patch-clamp technique. The recorded mEPSCs from motoneuron cultures were completely blocked by $20 \mu \mathrm{M}$ CNQX, a specific AMPA receptor blocker, suggesting that they were glutamatergic (Fig. 1D). This result was consistent with the previous study (Ullian et al., 2004) showing that primary cultured motoneurons form glutamatergic synapses with each other. Although primary motoneurons do secrete acetylcholine (Camu and Henderson, 1992; Martinou et al., 1992), it would be improbable to record acetycholinemediated mEPSCs given that motoneurons express none or few nicotinic acetylcholine receptors. Frequency and amplitude of mEPSC were measured. The mean frequency of mEPSC represents the amount of glutamate release from presynaptic sites, whereas the mean amplitude of mEPSCs represents the property of postsynaptic glutamate receptors. We observed an $\sim 58 \%$ reduction in mEPSC frequency $(p<0.001)$ but no change in mEPSC amplitude $(p=0.26)$ from SMA motoneurons, compared with that from WT motoneurons (Fig. $1 E, F$ ), indicating that SMN deficiency adversely affects presynaptic glutamate release without changing postsynaptic glutamate receptor function. To further confirm that glutamate receptors on motoneurons are not affected by SMN deficiency, we used $\mathrm{Ca}^{2+}$ imaging approach with fura-2 AM to record activation of glutamate receptors on WT and SMA motoneurons elicited by $100 \mu \mathrm{M}$ glutamate. The kinetics of intracellular calcium concentration $\left[\mathrm{Ca}^{2+}\right]_{\mathrm{i}}$ were quantified by the A340/A380 ratio (Fig. $1 G$ ). WT and SMA motoneurons displayed no difference in resting $\left[\mathrm{Ca}^{2+}\right]_{\mathrm{i}}$ level $(p=0.24)$ (Fig. $\left.1 H\right)$. In addition, no difference in the $\left[\mathrm{Ca}^{2+}\right]_{\mathrm{i}}$ response elicited by $100 \mu \mathrm{M}$ glutamate was detected between WT and SMA motoneurons $(p=0.35)$ (Fig. $1 I$ ). These results suggest that the function of glutamate receptors on motoneurons is not altered by SMN deficiency, which is also consistent with our patch-clamp data showing no change in mEPSC amplitude. Together, our results suggest that SMN deficiency in motoneurons, although not affecting motoneuron survival, results in reduced synapse formation and synapse transmission, demonstrating an intrinsic deficit of SMA motoneurons in synapse formation in vitro.

\section{SMN deficiency in astrocytes alters calcium concentrations}

Having demonstrated the intrinsic defects in SMA motoneurons, we then asked whether there were also intrinsic defects in SMA astrocytes. To address this question, we used pure astrocytes in culture and examined astrocyte $\mathrm{Ca}^{2+}$ signaling, which is regulated by cellular intrinsic properties and essential to neuronastrocyte communication in the brain (Perea and Araque, 2005; Araque, 2008).

In WT and SMA spinal astrocyte cultures, $>95 \%$ cells were positively stained by $\mathrm{S} 100$ antibody, an astrocyte marker, confirming the purity of the population (Fig. 2A). SMA astrocytes displayed similar cell density and size after $6 \mathrm{~d}$ of culture as WT astrocytes (Fig. 2B,C). At resting condition, SMA astrocytes had modest but significant lower basal $\left[\mathrm{Ca}^{2+}\right]_{\mathrm{i}}$ compared with WT astrocytes, as illustrated in Figure $2 D, E(p<0.0001)$. Applying $50 \mathrm{mM} \mathrm{KCl}$ evoked an increase in $\left[\mathrm{Ca}^{2+}\right]_{\mathrm{i}}$ in $>80 \%$ of WT or SMA astrocytes tested (WT: $n=94$ of 112, SMA: $n=156$ of 191), but the $\left[\mathrm{Ca}^{2+}\right]_{\mathrm{i}}$ increase (peak-baseline) was $\sim 25 \%$ higher 
in SMA astrocytes than that in WT astrocytes $(p<0.001$; Fig. $2 F, G)$. Similarly to $\mathrm{KCl}$, application of $10 \mu \mathrm{M}$ ATP evoked $\sim 25 \%$ greater increase of $\left[\mathrm{Ca}^{2+}\right]_{\mathrm{i}}$ in SMA astrocytes compared with WT astrocytes $(p<0.0001$; Fig. $2 H, I)$. These results indicate that SMN deficiency alters intracellular calcium signaling in astrocytes, which in turn may impair the communication between motoneurons and astrocytes. In contrast to our results shown here, a recent study has shown that astrocytes from SMA-induced pluripotent stem cells (iPSCs) have higher basal $\left[\mathrm{Ca}^{2+}\right]_{\mathrm{i}}$ and decreased response to ATP stimulation than control iPSC astrocytes (McGivern et al., 2013). The inconsistency may be due to the difference in species (human vs mouse) and preparations (human iPSC-derived astrocytes with the influence of other cell types in the same culture vs pure primary mouse spinal astrocytes). In addition, many astrocyte-specific genes (e.g., GFAP, S100 $\beta$, NFIA/B, GLAST, Sox9) are differentially regulated during astrocyte development (Cahoy et al., 2008; Molofsky et al., 2012); thus, it is likely that astrocytes at different maturation stages (adult vs neonatal) are molecularly and functionally different (Molofsky et al., 2012).

\section{SMN deficiency alters motoneuron- astrocyte interactions in synapse formation and function in contact cocultures}

Given that SMA astrocytes have abnormal calcium signaling (Fig. 2) and SMN restoration in astrocytes mitigates SMA disease pathologies (Rindt et al., 2015), SMN deficiency in astrocytes might alter normal motoneuron-astrocyte interactions. To address whether SMA astrocytes are involved in motoneuron dysfunction and loss in SMA, we used a coculture system in which motoneurons were directly plated onto a feeder layer of astrocytes (illustrated in Fig. 3A).

First, to examine whether SMN deficiency in astrocytes affect neuronal survival, WT or SMA astrocytes were cultured with WT or SMA motoneurons for 12-14 DIV and neuronal survival was quantified using $\mathrm{Hb} 9$ antibody staining (Fig. 3B). We observed that astrocytes, regardless of their genotypes, significantly enhanced the survival of WT and SMA motoneurons by $\sim 8$-fold $(p<0.01,3$ experiments per condition; Fig. $3 C$, bars $1-4)$ compared with pure motoneuron cultures (Fig. $3 C$, bars 5,6 ), which is consistent with previous studies that astrocytes promote motoneuron survival in vitro (Ullian et al., 2004). Interestingly, the survival of WT and SMA motoneurons did not differ when cocultured with WT or SMA astrocytes (Fig. 3C, bars 1-4; $p>0.05,3$ experiments per condition, one-way ANOVA). These results demonstrate that SMA astrocytes are capable of promoting motoneuron survival to the same degree as WT astrocytes in vitro.
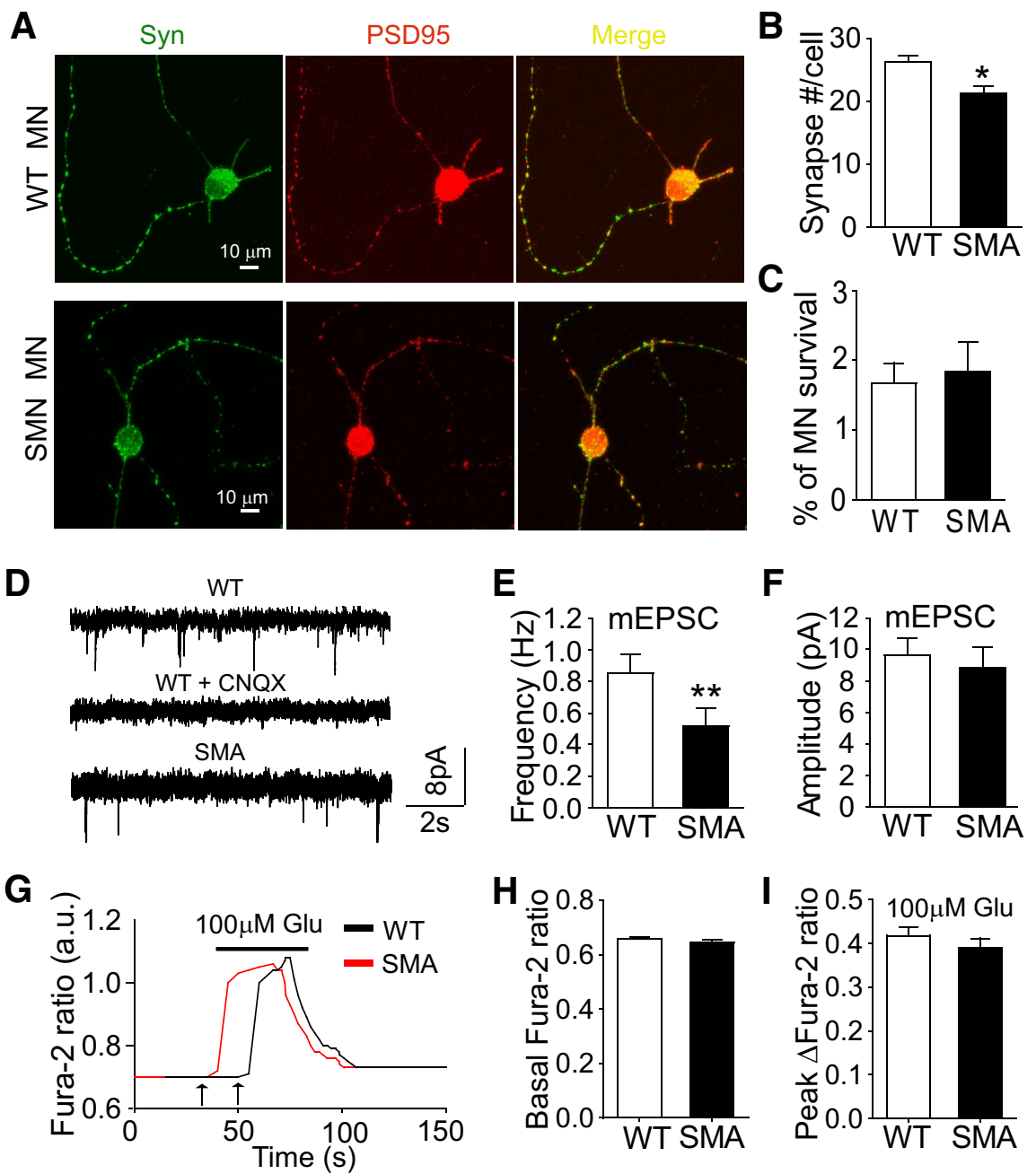

$\mathbf{F}$
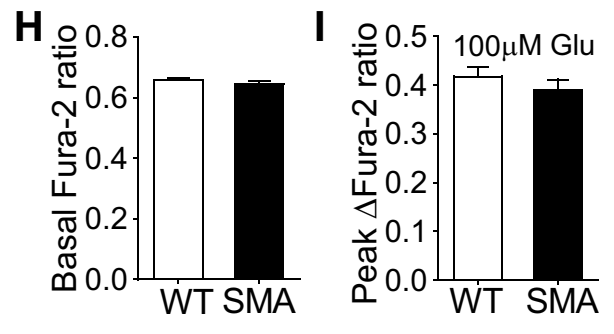

Figure 1. SMN deficiency in motoneurons impairs synapse formation and synaptic transmission. $\boldsymbol{A}$, Representative images of a SMA motoneuron (MN) immunostaining with specific antibodies against presynaptic and postsynaptic markers, synaptostaining. B. Synapse number per cell is significantly decreased in SMA motoneurons than that in WT motoneurons (WT: $26.2 \pm 0.9$ 71, SMA: $21.2 \pm 1.1, n=71) . p<0.001$ (unpaired $t$ test). C, SMA motoneurons display normal survival as WT motoneurons which can be blocked by CNQX. $\boldsymbol{F}, \boldsymbol{F}$. The frequency $(\boldsymbol{F})$ but not amplitude $(\boldsymbol{F})$ of mEPSC is decreased on SMA motoneurons, compared with that on WT motoneurons (frequency: WT, $0.76 \pm 0.19 \mathrm{~Hz}, n=35 ; \mathrm{SMA}, 0.34 \pm 0.18 \mathrm{~Hz}, n=35 ; p<0.001$, unpaired $t$ test; amplitude:WT, $9.7 \pm 1.1 \mathrm{pA} ; \mathrm{SMA}, 8.8 \pm 1.3 \mathrm{pA} ; p=0.24$, unpaired $t$ test). $\mathbf{G},\left[\mathrm{Ca}^{2+}\right]_{\mathrm{i}}$ increase elicited by $100 \mu \mathrm{M}$ glutamate. Arrow indicates application of glutamate. $\boldsymbol{H}, \boldsymbol{I},\left[\mathrm{Ca}^{2+}\right]_{\mathrm{i}}$ basal level $(\boldsymbol{H})$ and $\left[\mathrm{Ca}^{2+}\right]_{\mathrm{i}}$ increase with $100 \mu \mathrm{m}$ glutamate application (I) in WT and SMA motoneurons (calcium basal level: WT, $0.66 \pm 0.008, n=75 ; S M A, 0.64 \pm 0.009 n=63 ; p=0.24$, unpaired $t$ test). ${ }^{*} p<0.05 .{ }^{* *} p<0.01$. Error bars indicate SE.

Next, we tested whether the formation of synapses onto motoneurons is impaired by SMN deficiency in astrocytes. We found that more synapses were formed in WT motoneurons cocultured with WT astrocytes (Fig. $4 A, B$, bar 1 ) than synapses formed in WT motoneurons cultured alone (Fig. 4A, $B$, bar 5), which is consistent with a previous study (Ullian et al., 2004). The addition of SMA astrocytes also increased synapse number in WT motoneurons (Fig. 4A, B, bars 2, 5). However, a significant $\sim 40 \%$ reduction in synapse number was observed in WT motoneurons cocultured with SMA astrocytes (Fig. 4A, $B$, bar 2) compared with cocultured with WT astrocytes (Fig. $4 A, B$, bar 1). These results suggest that SMA astrocytes have defects in promoting synapse formation in vitro. In addition, we observed that WT astrocytes promoted synapse formation in SMA motoneurons by $\sim 2$-fold compared with SMA motoneurons alone (Fig. 4B, bars 
A
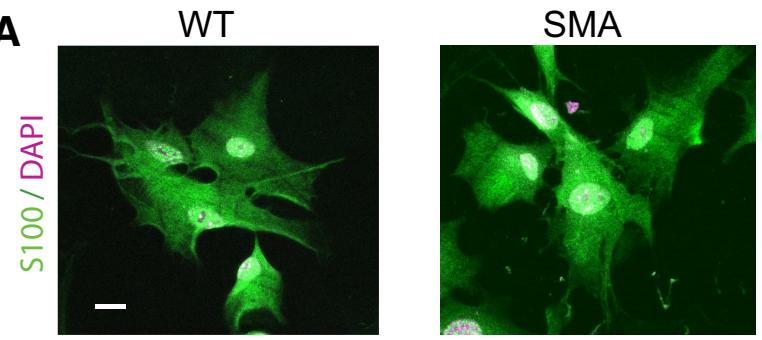

B

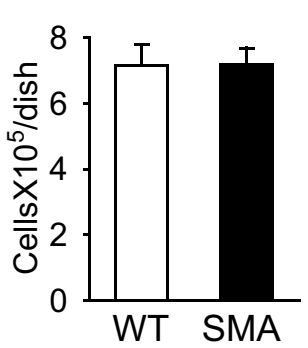

C
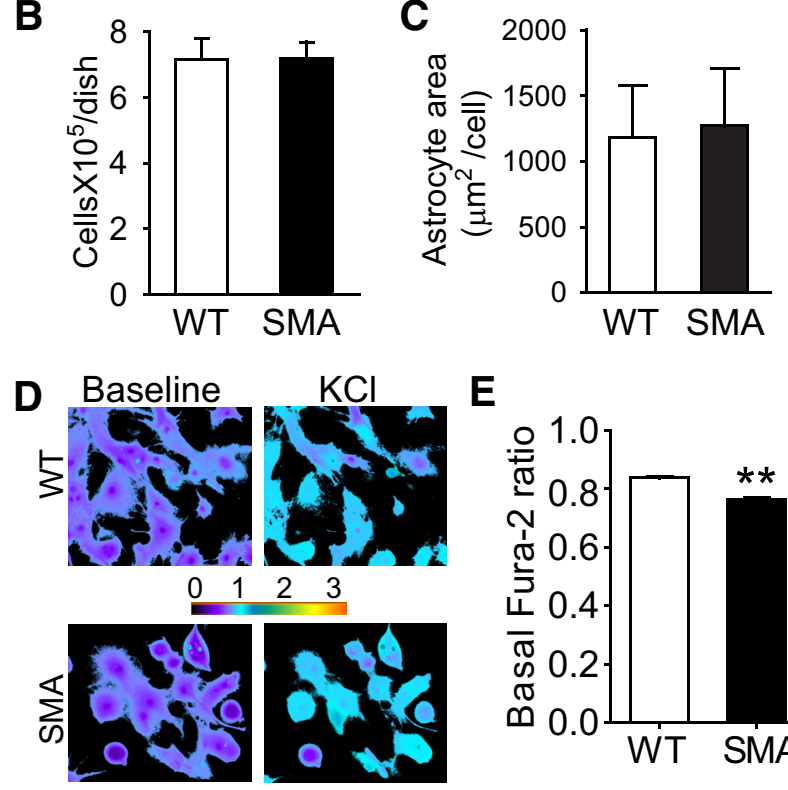

E

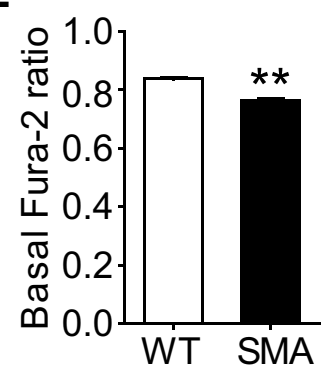

$\mathbf{F}$
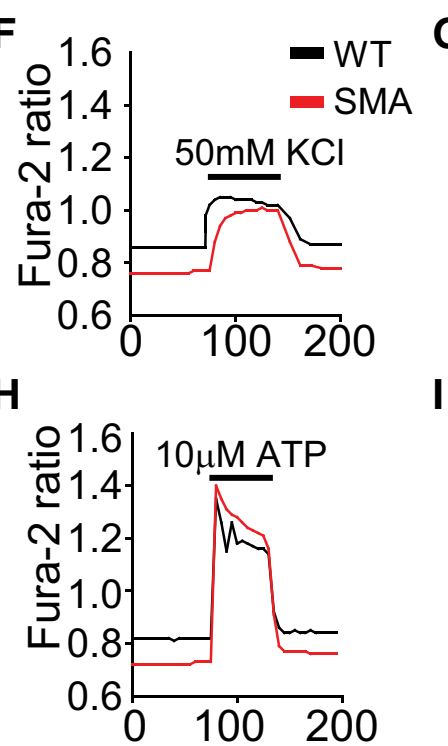

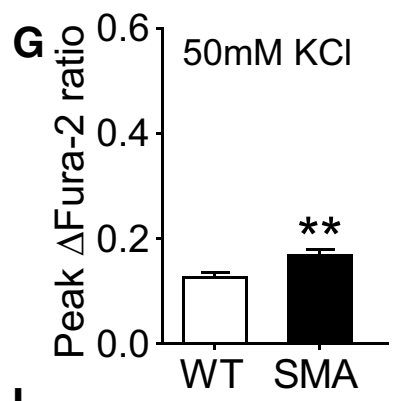

I

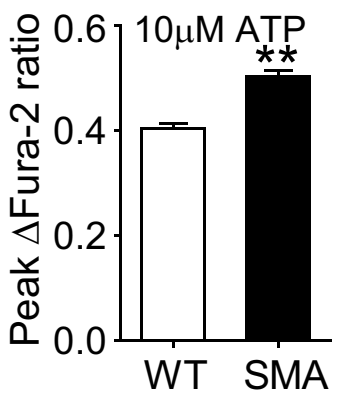

Figure 2. SMN deficiency in astrocytes alters calcium signals. $\boldsymbol{A}$, WT and SMA spinal astrocytes immunostaining with S100 antibody (green) and DAPI (magenta). Scale bar, $25 \mu \mathrm{m}$. $\boldsymbol{B}$, WT astrocytes and SMA astrocytes show a similar cell density $6 \mathrm{~d}$ after culture. Astrocytes are plated in $35 \mathrm{~mm}$ dishes. Average cell number is counted on day 6 from 4 dishes in each group. $\boldsymbol{C}$, WT and SMA astrocytes show similar cell size. Area of individual astrocyte is analyzed from $>200$ astrocytes in each group. D, Pseudocolored Fura2 fluorescence imaging in WT and SMA astrocytes shows rise of $\left[\mathrm{Ca}^{2+}\right]_{i}$ concentration with $50 \mathrm{~mm} \mathrm{KCl}$ application. $\boldsymbol{E}_{,}\left[\mathrm{Ca}^{2+}\right]_{\mathrm{i}}$ basal level is significantly lower in SMA astrocytes than that in WT astrocytes (WT: $0.84 \pm 0.007$ a.u., $n=102 ;$ SMA: $0.76 \pm 0.006$ a.u., $n=162 ; p<0.001$, unpaired $t$ test). $\boldsymbol{F}_{,}\left[\mathrm{Ca}^{2+}\right]_{\mathrm{i}}$ increase elicited by $50 \mathrm{~mm} \mathrm{KCl}$. G, SMA astrocytes have stronger increase of $\left[\mathrm{Ca}^{2+}\right]_{\mathrm{i}}$ to $\mathrm{KCl}$ application than WT astrocytes (WT, $0.13 \pm 0.0$ a.u., $n=110$; SMA, $0.17 \pm 0.01$ a.u., $n=174 ; p<0.001$,

$3,6)$, but the synapse number did not reach the level of WT motoneurons cocultured with WT astrocytes (Fig. 4B, bars 1,3). Thus, these data indicate that, in addition to the cell-autonomous defect, SMA motoneurons also display a defective response to astrocyte-derived signals. Furthermore, synapse numbers were at the same level between cocultures of SMA motoneurons with WT astrocytes and SMA motoneurons with SMA astrocytes (Fig. 4B, bars 3,4$)$. These data suggest that the synapse formation deficit in SMA may be due to a defect in the interactions between motoneurons and astrocytes. That is, defects of either component causes deficit in motoneuron synapse formation.

To investigate whether the reduction of synapse numbers on motoneurons upon SMN deficiency could lead to impaired synaptic transmission, we performed whole-cell patch-clamp recordings of mEPSCs from motoneurons (WT or SMA) in contact cocultures at 12-14 DIV (Fig. 4C). In WT motoneurons cocultured with WT astrocytes, we recorded a $\sim 3$.0-fold increase in mEPSC frequency compared with that in WT motoneurons alone (Fig. 4D, bars 1,5). The frequency of mEPSCs on WT motoneurons was also increased when cocultured with SMA astrocytes compared with that in WT motoneurons alone (Fig. 4D, bars 2,5 ). However, there was an $\sim 46 \%$ reduction of mEPSC frequency between WT motoneurons cocultured with SMA astrocytes and WT motoneurons cocultured with WT astrocytes (Fig. 4D, bars 1, 2). This result suggests that SMA astrocytes exhibit a defect in enhancing synaptic function in motoneurons. In SMA motoneurons cocultured with either WT or SMA astrocytes, there was also a significant increase in mEPSC frequency compared with that of SMA motoneurons alone (Fig. 4D, bars 3, $4,6)$. These data suggest that astrocytes from both WT and SMA are capable of enhancing synaptic function even in SMA motoneurons. However, there was still a significant reduction in mEPSC frequency compared with that in WT motoneurons cocultured with WT astrocytes (Fig. 4D, bars 1, 3, 4), indicating a defective response of SMA motoneurons to astrocyte signaling. Analysis of mEPSC amplitude revealed that the mean amplitude of mEPSCs on WT motoneurons was increased by $\sim 60 \%$ in the presence of WT astrocytes ( $p<0.05$; Fig. $4 E$, bars 1,5 ), consistent with a previous study showing that astrocytes enhance postsynaptic AMPA receptor responsiveness (Ullian et al., 2004). We also noticed that, regardless of their genotypes, astrocytes increased the mean amplitude of mEPSCs on either WT or SMA motoneurons ( $p<0.05$; Fig. $4 E$, bars $1-4$ vs bars 5,6$)$ to a similar level, implicating that SMN deficiency on either astrocytes or motoneurons has little effect on postsynaptic AMPA receptors. Our data show that SMN deficiency impairs motoneuron-astrocyte cross talk and leads to defects in both synapse formation and function.

SMN deficiency does not alter motoneuron excitability It is possible that the reduced synaptic activity of motoneurons driven by SMN deficiency (Fig. 4D) may be associated with the change in motoneuron excitability. To test this hypothesis, we recorded evoked action potential upon increasing hyperpolarizing or depolarizing current injection. Action potential threshold and intrinsic membrane properties were analyzed and compared between WT and SMA motoneurons when cultured with or with-

unpaired $t$ test). $\boldsymbol{H},\left[\mathrm{Ca}^{2+}\right]_{\mathrm{i}}$ increase elicited by $10 \mu \mathrm{M}$ ATP. I, SMA astrocytes have stronge increase of $\left[\mathrm{Ca}^{2+}\right]_{\mathrm{i}}$ to ATP application than WT astrocytes (WT, $0.4 \pm 0.009$ a.u., $n=240 ;$ SMA, $0.5 \pm 0.01$ a.u., $n=236 ; p<0.001$, unpaired $t$ test). ${ }^{* *} p<0.01$. Error bars indicate SE. 
A

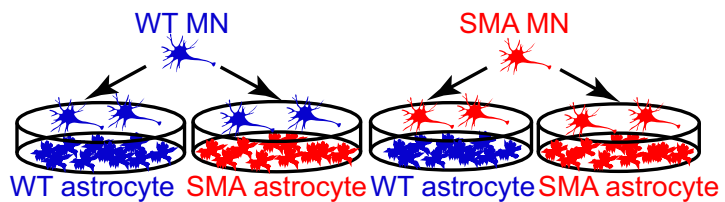

B

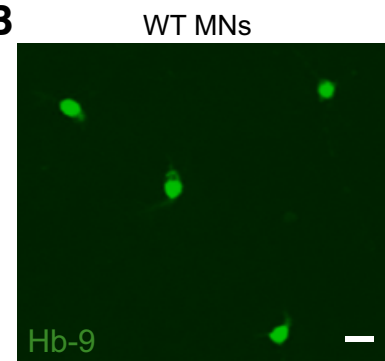

WT MNs + WT Astrocytes

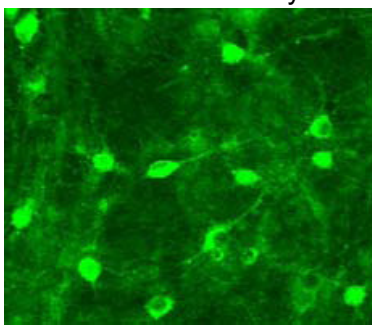

SMA MNs + WT Astrocytes

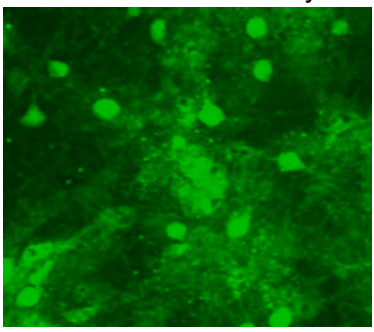

C

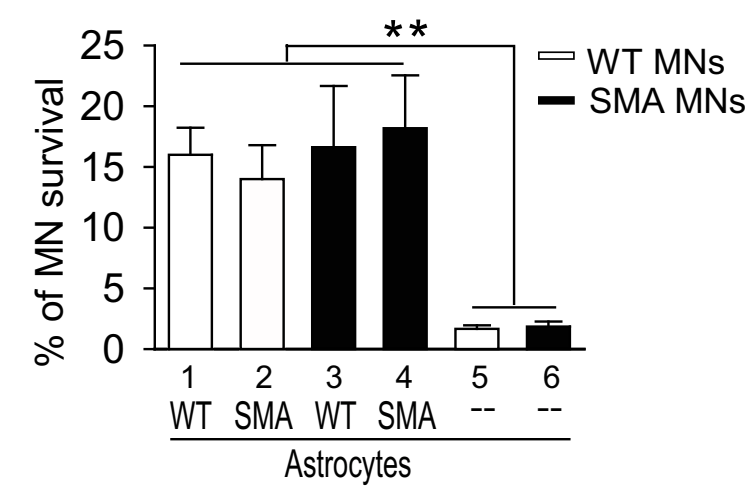

Figure 3. Motoneuron survival is not changed in motoneuron-astrocyte cocultures by SMN deficiency. $\boldsymbol{A}$, Schematic diagram of motoneuron astrocyte contact cocultures. Motoneurons (WT or SMA) are grown on a feeder layer of astrocytes (WT or SMA) allowing physical contacts between motoneurons and astrocytes. $\boldsymbol{B}$, Representative images of WT or SMA motoneurons grown alone or in astrocyte contact cocultures. The motoneurons are stained with $\mathrm{Hb} 9$ antibody (green). Scale bar, $20 \mu \mathrm{m}$. C, The survival of motoneurons in contact cocultures. The survival of SMA motoneurons does not differ from WT motoneurons in culture alone (WT, bar 5: $1.7 \pm 0.3 \%$; SMA, bar $6: 1.8 \pm 0.4 \% ; p=0.75$ ). The survival of motoneurons (WT or SMA, bars 5,6 ) is significantly increased in the presence of either WT or SMA astrocytes (bars $1-4 ; p=0.005$, one-way ANOVA). In contrast, the survival of WT or SMA motoneurons shows no difference when cocultured with either WT or SMA astrocytes (WT MNs with WT astrocytes, bar 1: $16 \pm 2.2 \%$; WT MNs with SMA astrocytes, bar 2: $14 \pm 2.8 \%$; SMA MNs with WT astrocytes, bar 3: $16.6 \pm 5 \%$; SMA MNs with SMA astrocytes, bar 4: $18.2 \pm 4.4 \%) .{ }^{* *} p<0.01, n$ is equal to 4 different cell preparations. Error bars indicate SE. out WT or SMA astrocytes. We observed that both SMA and WT motoneurons were able to readily fire action potential upon depolarization current injection (Fig. $5 A$ ). Both resting membrane potential and rheobase current for evoked action potential did not differ between WT and SMA motoneurons (Table 2). Furthermore, there was no significant difference regarding resting membrane potential, input resistance, rheobase current, and voltage threshold on motoneurons (WT and SMA) in contact cocultures (Table 2). However, pure motoneuron cultures from both WT and SMA displayed similarly higher input resistance and rheobase current compared with those in motoneuron-astrocyte contact cocultures (one-way ANOVA, $p<0.05$; Table 2). Because cells with less surface area tend to have a greater input resistance (Mentis et al., 2011), we measured the size of motoneurons. The size of motoneuron when cultured alone was significantly smaller than that when cocultured with astrocytes (Fig. $5 B)$. Therefore, the change in input resistance and rheobase current of WT or SMA motoneurons cultured alone is likely due to the change in motoneuron size rather than SMN deficiency in motoneurons. These results indicate that motoneuron excitability is less likely affected by SMN deficiency in either motoneurons or astrocytes.

Reduction of synapse formation and function on motoneuron by SMN deficiency is not mediated by astrocyte-diffusible factors in vitro

It is known that astrocytes modulate synapse formation and maintenance through both direct contact machinery and astrocyte-diffusible factors, such as neurotrophic factors, tumor necrosis factor- $\alpha$, or synaptogenic molecules (Christopherson et al., 2005; Barker et al., 2008; Clarke and Barres, 2013). To examine whether the reduction of synapse formation is due to a defect of SMA astrocytes in contact support or a defect in the release of diffusible factors, we seeded motoneurons on coverslips and set coverslips on top of a feeder layer of astrocytes for coculture (Fig. $6 A)$. Such an approach using noncontact coculture allows astrocytes to interact with motoneurons through diffusible factors without physical contact.

In noncontact cocultures, astrocytes from WT or SMA significantly increased the survival of both WT and SMA motoneurons ( $p<0.05$; Fig. $6 B$, bars $1-4$ vs bars 5,6$)$. The result is similar to that in contact cocultures shown above (Fig. $3 C$ ). Additionally, the survival of WT motoneurons (grown above either WT or SMA astrocytes) was not different from SMA motoneurons (grown above either WT or SMA astrocytes) ( $p>0.05,3$ experiments per condition, one-way ANOVA; Fig. $6 B$, bars 1-4). The number of synapses formed on motoneurons in noncontact cocultures were at the same level in all four different combinations of motoneurons and astrocytes ( $p=0.54$, one-way ANOVA, 3 experiments in each condition; Fig. $6 C$ ). Consistent with these data, there was no significant difference in either mEPSC frequency $(p=0.63$, one-way ANOVA; Fig. $6 D)$ or amplitude $(p=$ 0.43, one-way ANOVA; Fig. $6 E$ ) in these noncontact cocultures. These data suggest that SMA astrocytes are capable of secreting diffusible factors for promoting synapse formation and function to the same level as WT astrocytes. Thus, synaptogenic deficits in SMA are less likely to be mediated by astrocyte-diffusible factors. The defect in contact support might be a major pathophysiological feature of motoneuron-astrocyte interactions in SMA.

\section{SMN deficiency alters Ephrin B2 expression in astrocytes}

Our findings (Figs. 4, 6) suggested that the defects in contact support may disrupt motoneuron-astrocyte interactions in 

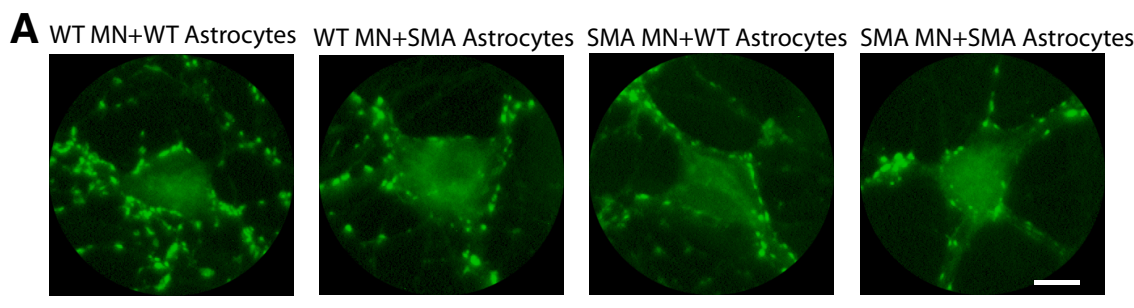

B

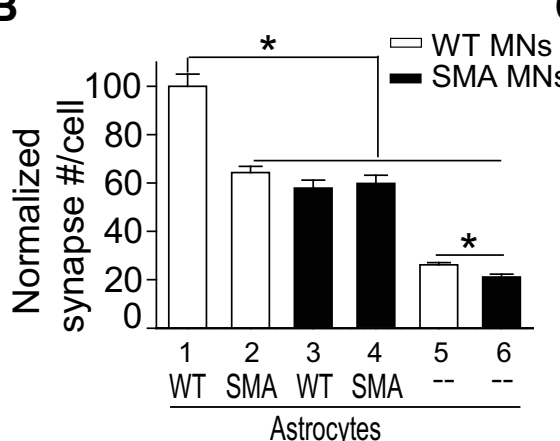

C

+ WT astrocyte
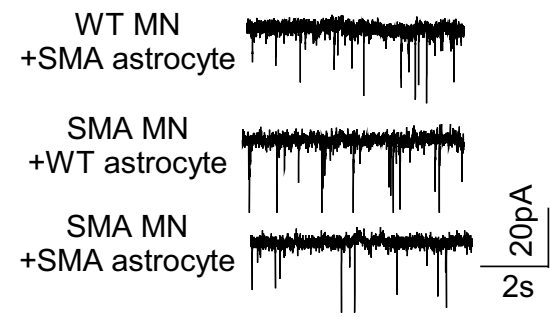

D

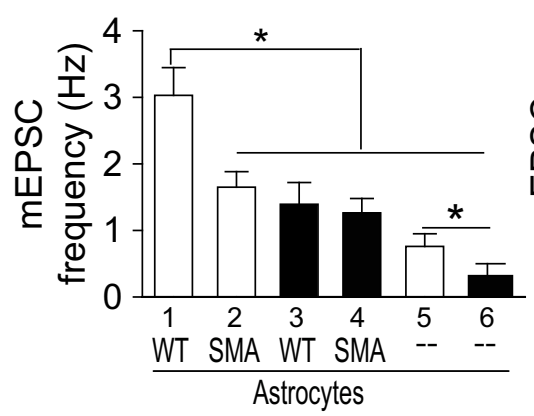

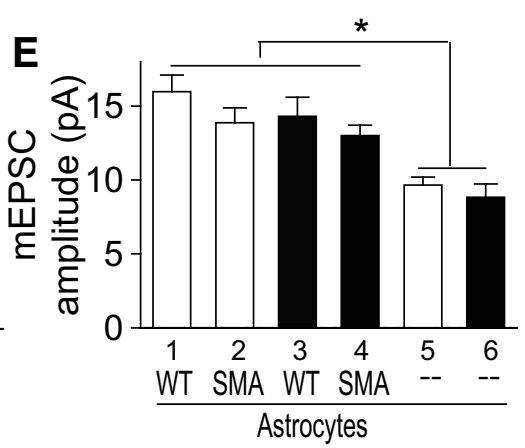

Figure 4. SMN deficiency alters motoneuron-astrocyte interactions in synapse formation and activation in contact cocultures. $\boldsymbol{A}$, Images of a motoneuron labeled with synaptophysin antibody for synapses (green) in contact cocultures. Scale bar, $10 \mu \mathrm{m}$. $\boldsymbol{B}$, Summary of normalized synapse number on motoneurons. SMA MNs (black bar) have less synapse number than WT MNs (white bar). Astrocytes from both WT and SMA significantly increase synapse number on either WT or SMA motoneurons. However, cocultures where deficiency of SMN in either MNs or astrocytes or both have less synapse number than WT MNs cocultured with WT astrocytes: WT MNs with WT astrocytes, bar 1: $100 \pm 5.1 \%$; WT MNs with SMA astrocytes, bar 2: $64.3 \pm 2.6 \%$; SMA MNs with WT astrocytes, bar 3:57.9 \pm 3.3\%; SMA MNs with SMA astrocytes, bar 4: $59.8 \pm 3.4 \%$; WT MN, bar 5: $26.2 \pm 0.9 \%$; SMA MN, bar 6: $21.1 \pm 1.1 \% ; n>30$ for each group. ${ }^{*} p<0.05$ (one-way ANOVA). C, Representative mEPSC traces recorded from either a WT or an SMA motoneuron in contact coculture. $\boldsymbol{D}, \boldsymbol{E}$, Summary of mEPSC frequency $(\boldsymbol{D})$ and amplitude $(\boldsymbol{E})$ on motoneurons. mEPSC frequency recorded on MNs shows similar trend as synapse number in $\boldsymbol{B}$. Astrocytes from both WT and SMA increase mEPSC amplitude on either WT or SMA MNs to a similar level (WT MNs with WT astrocytes, bar 1:3.0 $\pm 0.4 \mathrm{~Hz}$, $16 \pm 1.1 \mathrm{pA}$; WT MNs with SMA astrocytes, bar $2: 1.7 \pm 0.2 \mathrm{~Hz}, 13.9 \pm 1.0 \mathrm{pA}$; SMA MNs with WT astrocytes, bar $3: 1.4 \pm 0.3 \mathrm{~Hz}, 14.3 \pm 1.3 \mathrm{pA}$; SMA MNs with SMA astrocytes, bar $4: 1.3 \pm 0.2 \mathrm{~Hz}, 13.4 \pm 0.7 \mathrm{pA}$; WT MNs, bar 5: $0.76 \pm 0.19 \mathrm{~Hz}, 9.7 \pm 1.1 \mathrm{pA}$; SMA MNs, bar 6: $0.34 \pm$ $0.18 \mathrm{~Hz}, 8.8 \pm 1.3 \mathrm{pA}$ ). $n>25$ for each group. ${ }^{*} p<0.05$ (one-way ANOVA). Error bars indicate $\mathrm{SE}$.

SMA. We then explored the contact molecules that might be involved in these processes. It has been widely recognized that membrane binding ligands, Ephrins, originating from astrocytes, play positive roles in axon guidance and synapse development through binding to their neuron-bond receptors (Murai et al., 2003; O'Leary and McLaughlin, 2005; Lai and Ip, 2009). Ephrins are categorized into two types (Ephrin A and B) based on the properties of a glycosylphosphatidylinositol anchor or a transmembrane domain (Lai and Ip, 2009). The receptors for Ephrin A and Ephrin B are receptor tyrosine kinases, which are able to initiate intracellular signaling cascades. As astrocytes in murine express Ephrin A3, A4, and B2 (Ota et al., 2013), we used qRTPCR to detect mRNA levels of these subtypes of Ephrins in both WT and SMA primary cultured astrocytes (Fig. $7 A-C$ ). We found that, whereas the expression of Ephrin A3 and A4 was not changed, Ephrin B2 mRNA was reduced in SMA astrocytes by $\sim 73 \%$, compared with that in WT astrocytes $(p<0.05$, Fig. $7 C)$. It is possible that disruption of Ephrin B2 signaling may mediate impaired synapse formation on motoneurons in SMA.

\section{Discussion}

The present study used primary cultures of WT and SMA spinal motoneurons and astrocytes, to investigate their intrinsic deficits, as well as their interactions in SMA. First, SMA motoneurons alone exhibited intrinsic deficits in synapse formation and glutamatergic synaptic transmission. Second, SMA astrocytes had defects in calcium homeostasis, demonstrated by a lower basal $\left[\mathrm{Ca}^{2+}\right]_{\mathrm{i}}$ level but a stronger $\left[\mathrm{Ca}^{2+}\right]_{\mathrm{i}}$ increase to ATP application, in comparison with WT astrocytes. Third, in motoneuron and astrocyte cocultures, SMN deficiency in motoneurons, astrocytes, or both impaired the formation and function of synapse onto motoneurons, probably through a contact-dependent mechanism. Fourth, the transcript of contact molecule Ephrin B2 in SMA astrocytes was markedly reduced compared with WT astrocytes. Together, we demonstrate that, in SMA, there is a deficit in motoneuron-astrocyte contact interactions probably associated with downregulation of Ephrin B2, which could impair synapse formation.

\section{Intrinsic defects of SMA motoneurons} in synapse formation and function Previous studies from our and Mentis' groups have found decreases in synapse number and function on motoneurons in the SMA mouse model (Ling et al., 2010; Mentis et al., 2011). Here we used pure motoneuron cultures to specifically isolate and characterize dysfunction of motoneurons in SMA. We provide evidence that SMN deficiency causes intrinsic defect in synaptogenesis in motoneurons (Fig. 1). First, SMA motoneurons had $\sim 20 \%$ reduction in synapse number in comparison with WT motoneurons. Second, mEPSC frequency, but not amplitude, in SMA motoneurons was decreased compared with that in WT motoneurons. Other studies showed that SMN reduction causes axon development defect of motoneurons (McWhorter et al., 2003; Rossoll et al., 2003) and that SMNselective restoration in motoneurons is capable of restoring synapse numbers onto motoneurons (Gogliotti et al., 2012; Martinez et al., 2012). Our results confirm previous evidence in addition to supporting the hypothesis that SMN in motoneurons serves an important function in synapse formation and function (Rossoll et al., 2003; Park et al., 2010; Martinez et al., 2012). We also observed that SMA motoneurons displayed similar survival rate as WT motoneurons. The result is consistent with previous studies (Rossoll et al., 2003; Zhang et al., 2009), suggesting that synapse loss on motoneurons preceding motoneuron death in 

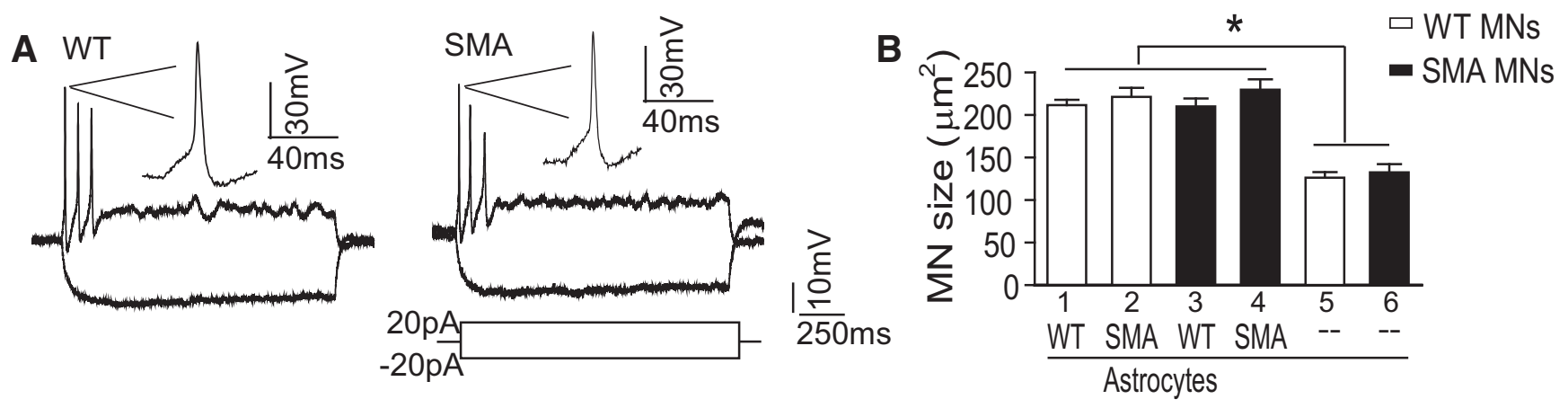

Figure 5. Electrophysiological properties and size of motoneuron are not changed by SMN deficiency. $\boldsymbol{A}$, Representative membrane potential changes in response to current injections in a WT and SMA motoneuron in culture alone. $\boldsymbol{B}$, Summary of cross-sectional area of motoneurons in astrocyte contact cocultures. The size of MNs (WT or SMA) is significantly enlarged in the presence of astrocytes (WT or SMA). However, motoneuron sizes are not changed by SMN deficiency (compare bars 1-4). WT MNs with WT astrocytes, bar 1: $211.5 \pm 6.1 \mu m^{2} ;$ WT MNs with SMA astrocytes, bar 2: $221.2 \pm 10.4 \mu \mathrm{m}^{2} ;$ SMA MNs with WT astrocytes, bar 3: $209.7 \pm 9.5 \mu \mathrm{m}^{2} ;$ SMA MNs with SMA astrocytes, bar $4: 229.5 \pm 12.3 \mu \mathrm{m}^{2} ;$ WT MNs cultured alone, bar 5: $126.1 \pm 6.6 \mu \mathrm{m}^{2} ;$ SMA MNs cultured alone, bar $6: 132.4 \pm 9.5 \mu \mathrm{m}^{2} . n>50$ for each group. ${ }^{*} p<0.05$ (unpaired $t$ test). Error bars indicate SE.

Table 2. Electrophysiological properties of motoneurons in astrocyte contact cocultures ${ }^{a}$

\begin{tabular}{|c|c|c|c|c|c|c|}
\hline Motoneurons & WT & WT & SMA & SMA & WT & SMA \\
\hline Astrocytes & WT & SMA & WT & SMA & - & - \\
\hline Resting membrane potential (mV) & $-56.6 \pm 1.8(12)$ & $-55.3 \pm 2.2(10)$ & $-63.5 \pm 3.0(8)$ & $-56.3 \pm 3.7(10)$ & $-53.60 .9 \pm 2.5(14)$ & $-55.7 \pm 3.2(9)$ \\
\hline Input resistance (m $\Omega$ ) & $545.5 \pm 51.2(12)$ & $525.0 \pm 126.1(10)$ & $469.2 \pm 73.1(8)$ & $425.0 \pm 72.7(10)$ & $1579 \pm 128(14)^{*}$ & $1128 \pm 84.4(9)^{*}$ \\
\hline C threshold (pA) & $33.8 \pm 8.3(12)$ & $411 \pm 3.2(10)$ & $41.2 \pm 12.9(8)$ & $33 \pm 8.6(10)$ & $14 \pm 1.9(14)^{*}$ & $16.7 \pm 2.9(9)^{*}$ \\
\hline V threshold (mV) & $-44.6 \pm 1.3(12)$ & $-41.9 \pm 2.1(9)$ & $-40.9 \pm 1.9(8)$ & $-44.2 \pm 2.2(10)$ & $-42.2 \pm 1.7(14)$ & $-42.6 \pm 2.4(9)$ \\
\hline
\end{tabular}

${ }^{a}$ The numbers of neurons are shown in parentheses.

${ }^{*} p<0.05$, compared with WT motoneurons plus WT astrocytes contact coculture (one-way ANOVA).

addition to disturbances in functional synaptic formation on motoneurons, may ultimately lead to motoneuron loss and behavioral abnormalities in SMA. The fact that significant motoneuron death occurs near the end stage (postnatal day 9) of $S M N \Delta 7$ mice (Le et al., 2005) supports a possibility that motoneurons might show neurodegenerative properties only after they have been maintained in culture for a prolonged period of time.

\section{Abnormal $\mathrm{Ca}^{2+}$ signal in SMA astrocytes}

Intracellular calcium signal in astrocytes plays important roles in their communication with neurons as it can trigger the release of glia transmitters, including glutamate, ATP, and prostaglandin E2, which in turn modulate synaptic transmission and plasticity (Verkhratsky and Steinhäuser, 2000; Haydon, 2001). The dysfunction of astrocyte calcium signaling has been reported in various pathological states, including epilepsy, Alzheimer's disease, and amyotrophic lateral sclerosis (Bezprozvanny, 2009; Kawamata et al., 2014). In pure astrocyte cultures, we found a dysfunction in calcium signaling in SMA astrocytes compared with WT astrocytes as demonstrated by lower resting $\mathrm{Ca}^{2+}$ concentration, and a stronger $\mathrm{Ca}^{2+}$ concentration increase in responses to ATP stimulation. The reduction in resting $\mathrm{Ca}^{2+}$ in SMA astrocytes suggests that SMN deficiency hampers the availability of calcium in astrocytes. Given that the increase of calcium in astrocytes cytoplasm by ATP stimulation is primarily mediated by calcium release from the endoplasmic reticulum after P2Y receptor activation (Verkhratsky, 2006), the increase of $\mathrm{Ca}^{2+}$ flux in SMA astrocytes in response to ATP application (Fig. 2G) suggests that either purinergic receptors on membrane or calcium storage/release from the endoplasmic reticulum were modified by SMN deficiency. Alterations of $\mathrm{Ca}^{2+}$ homeostasis in SMA astrocytes may impair physiological roles, which include regulation of neuronal synaptogenesis, proliferation, glutamate uptake, and release. Interestingly, we have found that SMN deficiency does not affect $\left[\mathrm{Ca}^{2+}\right]_{\mathrm{i}}$ signals in motoneurons (Fig. $1 G-I$ ), suggesting that the defects in calcium homeostasis following SMN deficiency are restricted to astrocytes.

\section{SMN deficiency disrupts motoneuron-astrocyte interactions} in synapse formation and synaptic transmission

In motoneuron-astrocyte contact cocultures (Fig. 4), we examined the role of motoneuron-astrocyte interactions in synapse formation and synaptic transmission onto motoneurons. We observed that SMA astrocytes were less supportive than WT astrocytes for synaptic formation and excitatory synaptic transmission onto WT motoneurons. However, WT astrocytes did not further improve synapse formation and synaptic transmission on SMA motoneurons in comparison with SMA astrocytes in our coculture system. Our data suggest that interactions between motoneurons and astrocytes might be disrupted due to SMN deficiency, and either motoneurons or astrocytes from SMA might contribute to the defects in synapse formation and synaptic transmission. Different from in vitro results here, our recent in vivo study has shown that selective SMN restoration in astrocytes actually increases synapse number onto motoneurons in SMN $\Delta 7$ mice (Rindt et al., 2015). One possible explanation is that, in our culture system, there are only motoneurons and astrocytes, as well as primary motoneurons forming synapses with each other. However, motoneurons in the spinal cord receive synaptic inputs from other neuron types, such as interneurons and sensory neurons. Selective SMN restoration in astrocytes may be beneficial not only to motoneurons but also to interneurons or sensory neurons, which may further improve maintenance of synapses on motoneurons in SMA mice.

One potential concern is that the reduced synapse numbers in WT motoneurons cocultured with SMA astrocytes could be secondary to a toxic effect of SMA astrocytes, as suggested in other 
A

Non-contact co-cultures

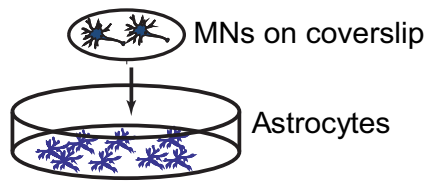

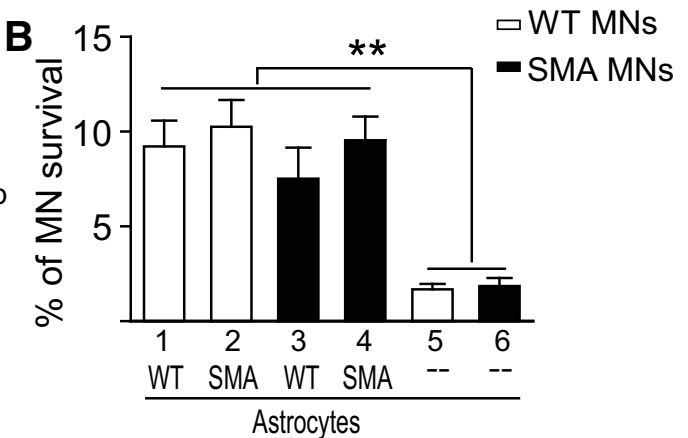
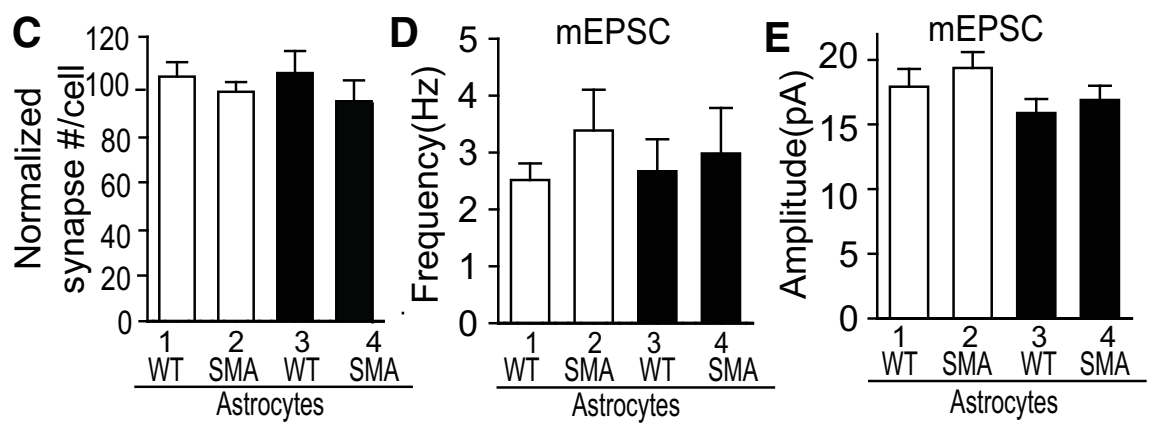

Figure 6. Synapse formation and function are not changed in motoneuron astrocyte noncontact cocultures. $\boldsymbol{A}$, Schematic diagram of noncontact cocultures. Motoneurons (WT or SMA) are seeded on coverslip and inserted in astrocytes (WT or SMA) cultures at day 0 for cocultures 12-14 DIV. $\boldsymbol{B}$, The survival of motoneurons in noncontact cocultures. Survival of MNs (WT or SMA) is significantly improved in the presence of astrocytes (WT or SMA) (WT MNs with WT astrocytes, bar 1:9.2 $\pm 1.4 \%$; WT MNs with SMA astrocytes, bar 2: $10.3 \pm 1.4 \%$; SMA MNs with WT astrocytes, bar 3:7.5 $\pm 1.6 \%$; SMA MNs with SMA astrocytes, bar 4: $9.5 \pm$ 1.2\%; WT MNs cultured alone, bar 5: $1.7 \pm 0.3 \%$; SMA MNs cultured alone, bar 6: $1.8 \pm 0.4 \%$ ). ${ }^{* *} p<0.01$ (one-way ANOVA). $n=3$ different cell preparations. C, Summary of normalized synapse number on motoneurons in noncontact cocultures (WT MNs with WT astrocytes, bar 1: $100 \pm 5.9 \%$; WT MNs with SMA astrocytes, bar 2: $93.7 \pm 4.0 \%$; SMA MNs with WT astrocytes, bar 3: $101.4 \pm 8.9 \%$; SMA MNs with SMA astrocytes, bar 4:89.9 $\pm 6.2 \%$ ). $n>30$ for each group, 3 experiments in each condition. $p=$ 0.54 (one-way ANOVA). $\boldsymbol{D}, \boldsymbol{E}$, Summary of mEPSC frequency $(\boldsymbol{D})$ and amplitude $(\boldsymbol{E})$ on motoneurons (WT MNs with WT astrocytes, bar 1: $2.5 \pm 0.3 \mathrm{~Hz}, 17.9 \pm 1.4 \mathrm{pA}$; WT MNs with SMA astrocytes, bar 2:3.4 $\pm 0.7 \mathrm{~Hz}, 19.4 \pm 1.2 \mathrm{pA}$; SMA MNs with WT astrocytes, bar $3: 2.7 \pm 0.7 \mathrm{~Hz}, 19.4 \pm 1.2 \mathrm{pA}$; SMA MNs with SMA astrocytes, bar 4:3.0 $\pm 0.8 \mathrm{~Hz}, 15.9 \pm 1.0 \mathrm{pA}) . n>25$ for each group. $p=$ 0.63 for frequency comparison. $p=0.43$ for amplitude comparison (one-way ANOVA). Error bars indicate SE.
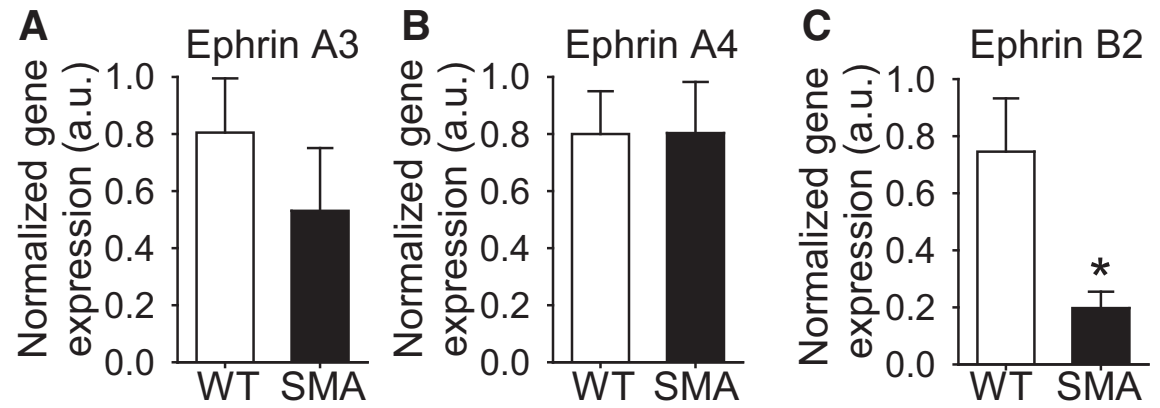

Figure 7. SMN deficiency alters Ephrin B2 expression in astrocytes. $\boldsymbol{A}-\boldsymbol{C}$, Quantification of mRNA expression of Ephrin A3, Ephrin $A 4$, and Ephrin B2 in astrocytes using quantitative RT-PCR. Ephrin A3:WT, $0.8 \pm 0.19 ; S M A, 0.53 \pm 0.22 ; p=0.37 ;$ Ephrin A4: WT, $0.8 \pm 0.15 ;$ SMA, $0.80 \pm 0.18, p=0.99 ;$ Ephrin B2: WT, $0.75 \pm 0.19 ;$ SMA, $0.20 \pm 0.06, p=0.02 ; n=6$ for each group. ${ }^{*} p<$ 0.05 (unpaired $t$ test). Error bars indicate SE.

neurological diseases, such as ALS and Rett syndrome (Di Giorgio et al., 2007; Nagai et al., 2007; Ballas et al., 2009). We ruled out such possibility because the survival of motoneurons in contact or noncontact cocultures was not affected when either motoneurons, astrocytes, or both were from SMA (Figs. 3, 6). Therefore, it is likely that SMA astrocytes exhibit a defect in providing synaptogenic support for motoneurons.

During neuronal communication, synaptic inputs drive dramatic membrane potential changes and alter firing patterns. One might anticipate that reduced excitatory synaptic inputs would lead to abnormal excitability in SMA motoneurons. However, we did not find changes in the excitability of SMA motoneurons (Fig. 5; Table 2). The result is contradictory with the hyperexcitability of SMA motoneurons observed in in vivo studies (Mentis et al., 2011; Gogliotti et al., 2012). The difference between in vitro and in vivo systems might account for the discrepancy. The hyperexcitability of motoneurons in in vivo studies may originate from motoneuron homeostatic reaction in response to reduced excitatory synaptic inputs, perhaps from the proprioceptive dorsal root ganglion neurons or spinal interneurons (Mentis et al., 2011).

Our observations from noncontact cocultures of motoneurons and astrocytes (Fig. 6) demonstrated that contact support from astrocytes contributes to the impaired interactions between motoneurons and astrocytes in SMA. In our experimental condition, all motoneuron cultures (contact and noncontact cocultures) were supplemented with neurotrophic factors (BDNF, GDNF, CNTF) (Ullian et al., 2004; Graber and Harris, 2013). Therefore, our data cannot rule out the possibility that SMA astrocytes might have defects in releasing diffusible factors in vivo.

It has been reported recently that SMA Schwann cells also exhibit intrinsic defects, and their interactions with motor axons are disrupted by SMN reduction, likely mediated by extracellular matrix defects, but not Schwann cell secreted factors (Hunter et al., 2014). Thus, it is likely that both astrocytes and Schwann cells contribute to the overall development of SMA pathology.

\section{Downregulation of Ephrin B2 in SMA astrocytes}

Among several contact molecules that contribute to contact interactions between motoneurons and astrocytes, we found, for the first time, that transcription of Ephrin B2 is reduced in SMA astrocytes (Fig. 7C). Considering that (1) Ephrin B2 coordinates development of both presynaptic and postsynaptic compartment and regulation of glutamatergic synaptogenesis (Kayser et al., 2006; McClelland et al., 2009) and (2) loss of Ephrin B2 results in specific defects in synapse formation in cortex neurons (Henkemeyer et al., 2003), it is therefore possible that EphrinB2 reduction in astrocytes could be a potential mechanism underlying the impaired synapse formation and glutamatergic synaptic transmission on SMA motoneurons. However, further investigation needs to be followed to understand the involvement of Ephrin $\mathrm{B} 2$ in SMA. 
In conclusion, the present study reveals critical pathophysiological signs of early-stage SMA: impaired contact-dependent interactions between motoneurons and astrocytes result in reduced synaptogenesis. SMA astrocytes display impairments in vitro in intracellular $\mathrm{Ca}^{2+}$ signaling, synaptic promotion function, and Ephrin B2 expression. It will be interesting to determine whether these impairments contribute to disease phenotypes in SMA animal models or patients as well. Together, our results indicate that astrocytes play a role in the pathogenesis of SMA and that targeting astrocytes, especially improving their contact communication with motoneurons, could be a potential therapy for SMA.

\section{References}

Allen NJ, Barres BA (2009) Neuroscience: glia-more than just brain glue. Nature 457:675-677. CrossRef Medline

Araque A (2008) Astrocytes process synaptic information. Neuron Glia Biol 4:3-10. CrossRef Medline

Ballas N, Lioy DT, Grunseich C, Mandel G (2009) Non-cell autonomous influence of MeCP2-deficient glia on neuronal dendritic morphology. Nat Neurosci 12:311-317. CrossRef Medline

Barker AJ, Koch SM, Reed J, Barres BA, Ullian EM (2008) Developmental control of synaptic receptivity. J Neurosci 28:8150-8160. CrossRef Medline

Barres BA (2008) The mystery and magic of glia: a perspective on their roles in health and disease. Neuron 60:430-440. CrossRef Medline

Bezprozvanny I (2009) Calcium signaling and neurodegenerative diseases. Trends Mol Med 15:89-100. CrossRef Medline

Boyer JG, Deguise MO, Murray LM, Yazdani A, De Repentigny Y, BoudreauLarivière C, Kothary R (2014) Myogenic program dysregulation is contributory to disease pathogenesis in spinal muscular atrophy. Hum Mol Genet 23:4249-4259. CrossRef Medline

Cahoy JD, Emery B, Kaushal A, Foo LC, Zamanian JL, Christopherson KS, Xing Y, Lubischer JL, Krieg PA, Krupenko SA, Thompson WJ, Barres BA (2008) A transcriptome database for astrocytes, neurons, and oligodendrocytes: a new resource for understanding brain development and function. J Neurosci 28:264-278. CrossRef Medline

Camu W, Henderson CE (1992) Purification of embryonic rat motoneurons by panning on a monoclonal antibody to the low-affinity NGF receptor. J Neurosci Methods 44:59-70. CrossRef Medline

Carmona MA, Murai KK, Wang L, Roberts AJ, Pasquale EB (2009) Glial ephrin-A3 regulates hippocampal dendritic spine morphology and glutamate transport. Proc Natl Acad Sci U S A 106:12524-12529. CrossRef Medline

Christopherson KS, Ullian EM, Stokes CC, Mullowney CE, Hell JW, Agah A, Lawler J, Mosher DF, Bornstein P, Barres BA (2005) Thrombospondins are astrocyte-secreted proteins that promote CNS synaptogenesis. Cell 120:421-433. CrossRef Medline

Clarke LE, Barres BA (2013) Emerging roles of astrocytes in neural circuit development. Nat Rev Neurosci 14:311-321. CrossRef Medline

Crawford TO, Pardo CA (1996) The neurobiology of childhood spinal muscular atrophy. Neurobiol Dis 3:97-110. CrossRef Medline

Di Giorgio FP, Carrasco MA, Siao MC, Maniatis T, Eggan K (2007) Non-cell autonomous effect of glia on motor neurons in an embryonic stem cellbased ALS model. Nat Neurosci 10:608-614. CrossRef Medline

Du W, Yu W, Huang L, Zhao M, Li X (2012) Ephrin-a4 is involved in retinal neovascularization by regulating the VEGF signaling pathway. Invest Ophthalmol Vis Sci 53:1990-1998. CrossRef Medline

Garcia O, Torres M, Helguera P, Coskun P, Busciglio J (2010) A role for thrombospondin-1 deficits in astrocyte-mediated spine and synaptic pathology in Down's syndrome. PLoS One 5:e14200. CrossRef Medline

Gogliotti RG, Quinlan KA, Barlow CB, Heier CR, Heckman CJ, Didonato CJ (2012) Motor neuron rescue in spinal muscular atrophy mice demonstrates that sensory-motor defects are a consequence, not a cause, of motor neuron dysfunction. J Neurosci 32:3818-3829. CrossRef Medline

Graber DJ, Harris BT (2013) Purification and culture of spinal motor neurons from rat embryos. Cold Spring Harb Protoc 2013:319-326. CrossRef Medline

Haidet-Phillips AM, Hester ME, Miranda CJ, Meyer K, Braun L, Frakes A, Song S, Likhite S, Murtha MJ, Foust KD, Rao M, Eagle A, Kammesheidt A, Christensen A, Mendell JR, Burghes AH, Kaspar BK (2011) Astrocytes from familial and sporadic ALS patients are toxic to motor neurons. Nat Biotechnol 29:824-828. CrossRef Medline

Hamilton G, Gillingwater TH (2013) Spinal muscular atrophy: going beyond the motor neuron. Trends Mol Med 19:40-50. CrossRef Medline

Haydon PG (2001) GLIA: listening and talking to the synapse. Nat Rev Neurosci 2:185-193. CrossRef Medline

Henkemeyer M, Itkis OS, Ngo M, Hickmott PW, Ethell IM (2003) Multiple EphB receptor tyrosine kinases shape dendritic spines in the hippocampus. J Cell Biol 163:1313-1326. CrossRef Medline

Hunter G, Aghamaleky Sarvestany A, Roche SL, Symes RC, Gillingwater TH (2014) SMN-dependent intrinsic defects in Schwann cells in mouse models of spinal muscular atrophy. Hum Mol Genet 23:2235-2250. CrossRef Medline

Iascone DM, Henderson CE, Lee JC (2015) Spinal muscular atrophy: from tissue specificity to therapeutic strategies. F1000Prime Rep 7:04. CrossRef Medline

Ilieva H, Polymenidou M, Cleveland DW (2009) Non-cell autonomous toxicity in neurodegenerative disorders: ALS and beyond. J Cell Biol 187: 761-772. CrossRef Medline

Jacobs S, Doering LC (2010) Astrocytes prevent abnormal neuronal development in the fragile X mouse. J Neurosci 30:4508-4514. CrossRef Medline

Kawamata H, Ng SK, Diaz N, Burstein S, Morel L, Osgood A, Sider B, Higashimori H, Haydon PG, Manfredi G, Yang Y (2014) Abnormal intracellular calcium signaling and SNARE-dependent exocytosis contributes to SOD1G93A astrocyte-mediated toxicity in amyotrophic lateral sclerosis. J Neurosci 34:2331-2348. CrossRef Medline

Kayser MS, McClelland AC, Hughes EG, Dalva MB (2006) Intracellular and trans-synaptic regulation of glutamatergic synaptogenesis by EphB receptors. J Neurosci 26:12152-12164. CrossRef Medline

Környei Z, Szlávik V, Szabó B, Gócza E, Czirók A, Madarász E (2005) Humoral and contact interactions in astroglia/stem cell co-cultures in the course of glia-induced neurogenesis. Glia 49:430-444. CrossRef Medline

Lai KO, Ip NY (2009) Synapse development and plasticity: roles of ephrin/ Eph receptor signaling. Curr Opin Neurobiol 19:275-283. CrossRef Medline

Le TT, Pham LT, Butchbach ME, Zhang HL, Monani UR, Coovert DD, Gavrilina TO, Xing L, Bassell GJ, Burghes AH (2005) SMNDelta7, the major product of the centromeric survival motor neuron (SMN2) gene, extends survival in mice with spinal muscular atrophy and associates with fulllength SMN. Hum Mol Genet 14:845-857. CrossRef Medline

Lefebvre S, Bürglen L, Reboullet S, Clermont O, Burlet P, Viollet L, Benichou B, Cruaud C, Millasseau P, Zeviani M, et al. (1995) Identification and characterization of a spinal muscular atrophy-determining gene. Cell 80: 155-165. CrossRef Medline

Ling KK, Lin MY, Zingg B, Feng Z, Ko CP (2010) Synaptic defects in the spinal and neuromuscular circuitry in a mouse model of spinal muscular atrophy. PLoS One 5:e15457. CrossRef Medline

Livak KJ, Schmittgen TD (2001) Analysis of relative gene expression data using real-time quantitative PCR and the 2(-delta delta C(T)) Method. Methods 25:402-408. CrossRef Medline

Martinez TL, Kong L, Wang X, Osborne MA, Crowder ME, Van Meerbeke JP, Xu X, Davis C, Wooley J, Goldhamer DJ, Lutz CM, Rich MM, Sumner CJ (2012) Survival motor neuron protein in motor neurons determines synaptic integrity in spinal muscular atrophy. J Neurosci 32:8703-8715. CrossRef Medline

Martinou JC, Martinou I, Kato AC (1992) Cholinergic differentiation factor $(\mathrm{CDF} / \mathrm{LIF})$ promotes survival of isolated rat embryonic motoneurons in vitro. Neuron 8:737-744. CrossRef Medline

McClelland AC, Sheffler-Collins SI, Kayser MS, Dalva MB (2009) Ephrin-B1 and ephrin-B2 mediate EphB-dependent presynaptic development via syntenin-1. Proc Natl Acad Sci U S A 106:20487-20492. CrossRef Medline

McGivern JV, Patitucci TN, Nord JA, Barabas ME, Stucky CL, Ebert AD (2013) Spinal muscular atrophy astrocytes exhibit abnormal calcium regulation and reduced growth factor production. Glia 61:1418-1428. CrossRef Medline

McWhorter ML, Monani UR, Burghes AH, Beattie CE (2003) Knockdown of the survival motor neuron (Smn) protein in zebrafish causes defects in motor axon outgrowth and pathfinding. J Cell Biol 162:919-931. CrossRef Medline

Mentis GZ, Blivis D, Liu W, Drobac E, Crowder ME, Kong L, Alvarez FJ, 
Sumner CJ, O’Donovan MJ (2011) Early functional impairment of sensory-motor connectivity in a mouse model of spinal muscular atrophy. Neuron 69:453-467. CrossRef Medline

Molofsky AV, Krenick R, Ullian E, Tsai HH, Deneen B, Richardson WD, Barres BA, Rowitch DH (2012) Astrocytes and disease: a neurodevelopmental perspective. Genes Dev 26:891-907. CrossRef Medline

Murai KK, Nguyen LN, Irie F, Yamaguchi Y, Pasquale EB (2003) Control of hippocampal dendritic spine morphology through ephrin-A3/EphA4 signaling. Nat Neurosci 6:153-160. CrossRef Medline

Nagai M, Re DB, Nagata T, Chalazonitis A, Jessell TM, Wichterle H, Przedborski S (2007) Astrocytes expressing ALS-linked mutated SOD1 release factors selectively toxic to motor neurons. Nat Neurosci 10:615-622. CrossRef Medline

Nicole S, Desforges B, Millet G, Lesbordes J, Cifuentes-Diaz C, Vertes D, Cao ML, De Backer F, Languille L, Roblot N, Joshi V, Gillis JM, Melki J (2003) Intact satellite cells lead to remarkable protection against Smn gene defect in differentiated skeletal muscle. J Cell Biol 161:571-582. CrossRef Medline

O'Leary DD, McLaughlin T (2005) Mechanisms of retinotopic map development: Ephs, ephrins, and spontaneous correlated retinal activity. Prog Brain Res 147:43-65. CrossRef Medline

Ota Y, Zanetti AT, Hallock RM (2013) The role of astrocytes in the regulation of synaptic plasticity and memory formation. Neural Plast 2013: 185463. CrossRef Medline

Paez-Colasante X, Seaberg B, Martinez TL, Kong L, Sumner CJ, Rimer M (2013) Improvement of neuromuscular synaptic phenotypes without enhanced survival and motor function in severe spinal muscular atrophy mice selectively rescued in motor neurons. PLoS One 8:e75866. CrossRef Medline

Park GH, Maeno-Hikichi Y, Awano T, Landmesser LT, Monani UR (2010) Reduced survival of motor neuron (SMN) protein in motor neuronal progenitors functions cell autonomously to cause spinal muscular atrophy in model mice expressing the human centromeric (SMN2) gene. J Neurosci 30:12005-12019. CrossRef Medline
Perea G, Araque A (2005) Properties of synaptically evoked astrocyte calcium signal reveal synaptic information processing by astrocytes. J Neurosci 25:2192-2203. CrossRef Medline

Pickles JO (2003) Expression of Ephs and ephrins in developing mouse inner ear. Hear Res 178:44-51. CrossRef Medline

Rindt H, Feng Z, Mazzasette C, Glascock JJ, Valdivia D, Pyles N, Crawford TO, Swoboda KJ, Patitucci TN, Ebert AD, Sumner CJ, Ko CP, Lorson CL (2015) Astrocytes influence the severity of spinal muscular atrophy. Hum Mol Genet 24:4094-4102. CrossRef Medline

Rossoll W, Jablonka S, Andreassi C, Kröning AK, Karle K, Monani UR, Sendtner M (2003) Smn, the spinal muscular atrophy-determining gene product, modulates axon growth and localization of beta-actin mRNA in growth cones of motoneurons. J Cell Biol 163:801-812. CrossRef Medline

Ruiz R, Casañas JJ, Torres-Benito L, Cano R, Tabares L (2010) Altered intracellular $\mathrm{Ca}^{2+}$ homeostasis in nerve terminals of severe spinal muscular atrophy mice. J Neurosci 30:849-857. CrossRef Medline

Shababi M, Lorson CL, Rudnik-Schöneborn SS (2014) Spinal muscular atrophy: a motor neuron disorder or a multi-organ disease? J Anat 224:1528. CrossRef Medline

Tisdale S, Pellizzoni L (2015) Disease mechanisms and therapeutic approaches in spinal muscular atrophy. J Neurosci 35:8691-8700. CrossRef Medline

Ullian EM, Sapperstein SK, Christopherson KS, Barres BA (2001) Control of synapse number by glia. Science 291:657-661. CrossRef Medline

Ullian EM, Harris BT, Wu A, Chan JR, Barres BA (2004) Schwann cells and astrocytes induce synapse formation by spinal motor neurons in culture. Mol Cell Neurosci 25:241-251. CrossRef Medline

Verkhratsky A (2006) Glial calcium signaling in physiology and pathophysiology. Acta Pharmacol Sin 27:773-780. CrossRef Medline

Verkhratsky A, Steinhäuser C (2000) Ion channels in glial cells. Brain Res Brain Res Rev 32:380-412. CrossRef Medline

Zhang HM, Robinson N, Gómez-Curet I, Wang W, Harrington MA (2009) Neuronal and network activity in networks of cultured spinal motor neurons. Neuroreport 20:849-854. CrossRef Medline 